BRAIN. Broad Research in Artificial Intelligence and Neuroscience

ISSN: 2068-0473 | e-ISSN: 2067-3957

Covered in: Web of Science (WOS); PubMed.gov; IndexCopernicus; The Linguist List; Google Academic; Ulrichs; getCITED; Genamics JournalSeek; J-Gate; SHERPA/ROMEO; Dayang Journal System; Public Knowledge Project; BIUM; NewJour; ArticleReach Direct; Link+; CSB; CiteSeerX; Socolar; KVK; WorldCat; CrossRef; Ideas RePeC; Econpapers; Socionet.

2022, Volume 13, Issue 1, pages: 17-28 | https://doi.org/10.18662/brain/13.1/266

\section{Foreign Language Competence Development of University Students and its Evaluation in the Context of Modern Neuroscience}

\author{
Ruslana DOVHANCHYNA ${ }^{1}$, \\ Roksolana POVOROZNYUK ${ }^{2}$, \\ Svitlana KYRYCHENKOㄹ, \\ Anastasiia PETROVA 4 , \\ Nataliia BAILIUK ${ }^{5}$, \\ Bogdana KOLODII6
}

${ }^{1}$ Taras Shevchenko National University of Kyiv, Educational and Scientific Institute of Philology, Kyiv, Ukraine, dovganchina@ukr.net

${ }^{2}$ Taras Shevchenko National University of Kyiv, Educational and Scientific Institute of Philology, Kyiv, Ukraine, salina.sunset@gmail.com

${ }^{3}$ Admiral Makarov National University of Shipbuilding, Mykolaiv, Ukraine, svitlana.kyrychenko@,nuos.edu.ua

${ }^{4}$ Vinnytsia Mykhailo Kotsiubynskyi State Pedagogical University, Vinnytsia, Ukraine, nastyapetroff@ukr.net

${ }^{5}$ Odessa Polytechnic State University, Odessa, Ukraine nataliia.bailiuk@,opu.ua

${ }^{6}$ Taras Shevchenko National University of Kyiv, Educational and Scientific Institute of Philology, Kyiv, Ukraine, danah13ua@gmail.com
Abstract: The article reviews the literature, the main trends and prospects for building and, to a greater extent, evaluation of foreign language competence with university students in the context of modern neuroscience. For the first time, neuroscientific aspects in the now common methods of evaluation of foreign language competencies are determined and the expediency of using the associative method as an effective development and evaluative tool is substantiated. It is found that the neuro-approach at the level of linguodidactics in the evaluation and building linguistic and communicative competencies with students is possible with appropriate and methodically modeled actualization of logical-associative relations of free subjective meanings of words and obligatory (paradigmatic) meanings. The international significance of the article lies in its summary nature related to the methods of evaluating foreign language competencies, determining the relative universality and accessibility of the associative method as the most accessible of the neurooriented and accessible to the average higher education language teacher.

Keywords: evaluation, neurocognitive mechanisms, subjectivity, methods, associative experiment.

How to cite: Dovhanchyna, R., Povoroznyuk, R., Kyrychenko, S., Petrova, A., Bailiuk, N., \& Kolodii, B. (2022). Foreign Language Competence Development of University Students and its Evaluation in the Context of Modern Neuroscience. BRAIN. Broad Research in Artificial Intelligence and Neuroscience, 13(1), 17-28.

https://doi.org/10.18662/brain/13.1/266 
Foreign Language Competence Development of University Students and its ... Ruslana DOVHANCHYNA, et al.

\section{Introduction}

Development and assessment of foreign language competencies in today's globalized world with new rapidly changing challenges is a significant problem. If previously the triad "knowledge - experience - skills" in foreign languages has been relevant for decades, now the configuration of competencies is different: it is necessary to develop and evaluate language ability taking into account natural neurocognitive processes that correlate with the ability to solve practical problems of today, potential for making flexible decisions, perspective orientation, etc. (Melnyk et al., 2019; Nerubasska \& Maksymchuk, 2020; Onishchuk et al., 2020; Purpura, 2016).

For over a century, the world has used a scale of levels for foreign language proficiency from A1 (survival level) to C2 - the level of perfect command, but the content and functional meaning of these levels require a revision of the principles and methods of evaluating foreign language competence. Scientists point out that the next stage of revision of the developmental and evaluative principles of foreign language competence, which would take into account neurolinguistic, digital, intercultural and other new conditions, is currently relevant (Turnbull, 2017).

Modern linguodidacts (even those who have no command of the basics in neuroscience) intuitively understand: a professional bilingual should possess a foreign language in compliance with such psychologically and neurophysiologically oriented principles as naturalness, automatism, speed of speech reaction, authenticity, flexibility (García, 2017). Reforming a foreign language education should combine scientific and natural approaches (Creese et al., 2014; Melnyk et al., 2021; Nerubasska et al., 2020). All this suggests the need for a comprehensive tetralateral (four-aspect) approach in building and evaluation of foreign language competencies: taking into account neurophysiology - the needs of interpersonal communication intercultural communication - digital communication. If taking only a personal plan, then foreign language competence still looks more widespread than $10-20$ years ago. A professional bilingual is a person who can not only communicate in a foreign language in order to solve professional problems, but also argue, transform, illustrate with facts and opinions, determine contexts, draw conclusions, make hypotheses, etc. As we can see, these complex (although, at first glance, partial) competencies show a close connection with the neuropsychological category of active subjectivity, reflexivity and activity.

On the other hand, it is necessary to build competencies that are inherent and manifested in the group of native speakers: typical associations, 
concepts (mental linguistic formations), language efficiency of the team, corporate language, etc.

Despite the importance of analysis and description of the collective psycholinguistic portrait of firms, companies and corporations in terms of their speech and communication efficiency (see next section) at the present stage it is clear: only the principle of building and evaluation "from bottom up to top" gives good result in terms of valid evaluation and developing foreign language competencies. At the same time, a great importance belongs to the self-assessment and awareness of the subject in the linguodidactic process, its naturalness and connection with the existing conditions of communication, which determines the nature of modern higher linguistic education.

Finally, the fact that modern students find it most difficult to construct spontaneous and improvised oral speech, which indicates problems in the levels and depth of internalization of a foreign language, gives special relevance to the topic of this article. This encourages the search for methods of development and evaluation of foreign language competencies, taking into account natural neuropsychological patterns. Markers of high neurocognitive learning of a foreign language are the lack of stress, flexibility, associativity, appropriateness of the use of psycho-energy resources, the ability to switch, etc.

Thus, the aim of the article is to analyze methods of building and evaluation of foreign language competencies with students in terms of neuroscientific approach and justification of one of these methods as relatively accessible and universal for language teachers who do not have special neurophysiological knowledge and appropriate equipment.

\section{Neuroscientific aspects of evaluation of mental and neurological processes in learning - perception - use of a foreign language}

Modern neuroscience, which is deeply integrated with the humanities, takes a new approach to the problem of evaluating language and other socionic competencies. Thus, S. Volk, T. Köhler and M. Pudelko consider evaluation of a foreign or second language not in terms of the interpersonal effect of the use of foreign languages, but in terms of "intrapersonal, cognitive processes that affect overall performance of employees" (Volk et al., 2014). Scientists believe that it is necessary to develop evaluation models that take into account the cognitive processing of perception and reproduction of a foreign language. From the point of view of resourcefulness such processing is energy consuming and nonlinear. That 
is, it gradually depletes mental resource, which "can lead to biased decisionmaking and reduced self-regulation" (Volk et al., 2014). This approach is valid for group (collective) evaluation of the use of corporate foreign language, which affects activities of the organization, has practical implications for business, socionics and service sphere.

However, the main problem of the neuroscientific approach to foreign language evaluation is whether it is possible to use the tools of neuroimaging of lexical-semantic and grammatical cognitive processing of information by a bilingual. On the other hand, the problem arises as to "whether it is possible to process L2 by the same neural mechanism underlying collection and processing of L1" (second language and first language) (Abutalebi, 2008). J. Abutalebi provides experimental evidence that the second language is learned on the basis of the same neurostructures as the first one. However, since the second (foreign) language is studied, as a rule, by a more mature person, its neural assimilation occurs at "more expanded activity of the nervous system" (Abutalebi, 2008). These developments can be used in the humanities (pedagogy, psychology) in the evaluation of language competencies, if taking into account: cognitive processing of the native language is stronger and more automated, and a foreign one is less fixed by experience and weaker, it is less automated (more controlled by the individual). It is also possible to neurovisually study "competition and conflict" between languages, which can expand the range of diagnostic tools in the socio-humanities.

In neuroscientific approaches to evaluation of foreign language competencies, the concept of "control" appears more often than "monitoring" and "evaluation". Neuroscientists focus not so much on measuring linguistic knowledge as on issues of language representation, efficiency, and management, which can be measured by neuroimaging methods and analyzed by an appropriate methodological categorical apparatus. So far, despite significant advancement in neuroscience, a direct link between neural representation of the "second language" and its functional efficiency with an individual has not been found. However, it is proved that "speech production by bilinguals is a dynamic process that includes cortical and subcortical structures that use excitation / inhibition processes to solve problems of lexical competition when choosing language tools" (Abutalebi \& Green, 2007). This pattern can be used in the development of actual pedagogical tools for "measuring" the relationship between native and foreign languages.

Evaluation and control of language competence at a team (company) level can generate data on the overall psychological portrait of the group, 
and hence its effectiveness. Thus, in 2009 an evaluation of the foreign language competence of subsidiaries of Finland and China was conducted. These companies were located abroad. Structured interviews with the company management and their psycholinguistic and performance analysis showed that "subsidiaries with low language competence were controlled more by centralization and formalization than divisions with high language competence" (Björkman \& Piekkari, 2009). At the same time, the language competence of the support staff had almost no effect on the psycholinguistic portrait of the company. Such studies prove relevance of psycho and neurolinguistic control of the core of the team (group), which determines its linguistic and social effectiveness in general.

Neuropsychologists have also suggested that the use of a foreign language should cause a slowdown in thinking by increasing load on the areas responsible for information processing. The latter is generated mentally in the native language and is subject to simultaneous internal translation. The truth of this hypothesis was proved by conducting an experiment with divided attention (the experiment involved Anglo-Japanese and Japanese-English bilinguals) (Takano \& Noda, 1993). Certain theses from the results of this study can be used in linguodidactics, specifically: a) decrease in mental activity differs from difficulties of translation; b) the efficiency of language tasks in a foreign language is always lower than in the native language; c) decreased mental efficiency is observed even in other types of thinking (when performing several unrelated tasks).

Neuropsychological studies were also performed to determine whether there was a noticeable additional load on the total working memory (WM) in the perception of a foreign language. The following thesis was postulated: the native language is fully automated, a foreign one - partially. At that, participants of the experiment evaluated themselves the sentences heard in a foreign language in terms of understanding and memorized the last word of each sentence by recognizing the displayed pictures. At the same time, the sentences increased in size each time, and after each act of perception it was necessary to remember all the last words. Simultaneously, duration of recalling was determined. The sentences alternated and were presented either in the native language of the participants of the experiment or in the second language learned. The result is predictable: perception and recollection of sentences in a foreign language created deficit of working memory, and the quality and accuracy of recollection-reproduction in the native language was higher (Service et al., 2002). Similar experiments were performed on the processing of written texts, phonological short-term memory and language differences/similarities. The general principle relevant 
for linguodidactics was made: with practice the speed and quality of comprehension of sentences in a foreign language increases, and the load on the resources of thinking and memory decreases. Such psycholinguistic evaluation can also be considered as a multifaceted time-stretched evaluation.

Analysis of the above neuro-oriented linguodidactic literature shows that it is necessary to look for neurolinguistic aspects in the actual didactic methods in order to make it possible to take into account and use these aspects by the average teacher who has no special neuroscientific training and tools for neuroimaging of foreign language speech processes.

\section{Substantiation of associative formative-diagnostic experiment as a method "between didactics and neuro"}

In modern European universities there is a gradual departure from the universal method of testing and the like, and methods for determining foreign language knowledge, rather than functions have long been a thing of the past. Even in the post-Soviet republics from where the author comes from, traditional testing in foreign language learning is actively supplemented by natural ways of using language: establishing the amount of acquired meanings of words and their associations, spontaneous generation of oral and written foreign discourse, creative rather than reproductive methods, etc. It is clear that evaluation of foreign language competencies on the basis of a neuro-approach (it is a methodological reflection of the natural processes of speech thinking) should be diagnostic and formative. Communicative competencies, which are currently among the top five key competencies of the modern adult, are the main goal of the neurodidactic approach. Communication in a foreign language is a complex neurocognitive process that is developed, evaluated and functions syncretically, so it is necessary to teach and simultaneously monitor effectiveness of acquisition of bilingual status by students (Turnbull, 2017).

The search for a universal or at least the most accessible to the teacher neurolinguistically oriented method of building and evaluation of foreign language competencies, which would take into account all aspects, allowed to distinguish the associative experiment. Researchers point out that "such an experiment diagnoses not only knowledge of a foreign language, but also flexibility of thinking, the ability to establish syntagmatic and paradigmatic connections, feel the peripheral semantics of lexical items and use linguistic richness in generating coherent oral text" (Khirzoeva, 2008). At the same time, it is both a developmental and an evaluative method. 
This method uses both the actual language mechanisms and builds the actual language competencies (the ability to establish syntagmatic and paradigmatic connections, use linguistic richness in generating coherent oral text, feel the peripheral semantics of lexical items) and neurolinguistic (flexibility of thinking), establishing connections between referents and denotations of lexical items, feelings and expressions of the linguistic collective consciousness (concepts), etc.

Despite the fact that the language associative experiment was invented in the early XX century, only in the XXI century it got a new lease of life in the fold of cognitive, neuro- and psycholinguistics, as it correlates with the theory of neural connections. The latter in linguistic terms clearly manifests itself in mental linguistic theory (Thumb \& Marbe, 1901). Scientists suggest that the key concepts in the system of metaphorical, associative, logical linguistic connections are a specific cognitive (individual, and in most cases collective) construct - concept. It can be measured within the framework of an associative experiment both as a personal and as a corporate entity.

Instead, the classical approach to speech professional competencies offers to consider the necessary skills for knowledge of language units and their practical use (creation of oral or written speech). We agree that such first level of interiorization of a foreign language is validly evaluated through tests, translation and conversation. Instead, foreign speech as a product of deep neurostructures requires not only a logical but also an irrational individual approach, which is "diagnosed by constructing concepts in the form of a lexical-semantic field or, using an associative experiment, an associative-semantic field" (Sternin, 2001).

Obtaining a bachelor degree involves not only professional (from B 2), but also the most natural mastery of a foreign language, so we propose to diagnose the individual associative structure of the word by analogy with the structure of the concept. This process can be final in reflecting the associative experiment.

In order to confirm the effectiveness of the associative neurolinguistic method of building and evaluation of foreign language competencies, we briefly describe our own experience of its application.

On the basis of the Faculty of Foreign Languages, an associative experiment was conducted to evaluate foreign language competencies by establishing individual associations between full words of a foreign language. There are 5,000 to 6,000 such words in each Indo-European language, but the 50 most commonly used full words were chosen by random sampling. After that, the teacher read the lexical items in random order, and students 
had 5-7 seconds to record blitz associations. The maximum number of the latter was not limited and ranged from 3 to 7 in the control and experimental groups.

Professional mastery of a foreign language is not only knowledge of meanings of learned words, but also development of one's own idiostyle, development of usual and individual (occasional) linguistic neural connections. Scientists note: "These processes in a linear form occur almost unconsciously (actualization of the relationship between the referent and his verbal objectification)" (Khirzoeva, 2008) Therefore, such connections can be evaluated only indirectly and in an accelerated mode. Therefore, the associative experiment is the most valid: it allows to identify not so much semantic connections as connections between external stimuli-excitants, verbalized instantly. The speed and nature of associations allow to conclude about the quality of ownership and the degree of interiorization of foreign language units.

At the next stage of the linguistic associative experiment, we collected a maximum number of associations to a small number of words without time limit. At this stage, each student was offered one lexical unit and an unlimited amount of time (up to an hour or more). The student had the opportunity to comprehend and arbitrarily explain meanings and essence of the selected associations. At this stage, the maximum scope of the individual concept was clarified.

The last stage of the research is building an individual concept on the basis of all the maximum possible meanings of a single word and definition of its associative and subjective meanings. The method of free associations was used, which essentially illustrated logical and emotional thinking (emotional intelligence) taking into account all types of associations. At this stage, researchers propose to establish types of relationships, inventory associations and subjectively explain their origin (Sternin, 2001).

As it was confirmed, the most striking neuropsychological markers in the experiment were: a) the ratio of individual frequency of associations to the total number of lexical units; b) the presence of clichéd combinations in speech; c) psychological indicators (spontaneity, speed, emotionally colored values, intention, etc.).

Quantitative and qualitative methods, neuropsychological and linguistic interpretation of data, in particular correspondence of volume of obligatory and individual values of the individual dictionary, speed and quality of their reproduction were expediently used at processing of results. Such values were compared with those required for the content of education at this stage. Subsequently, such data were evaluated against the background 
of other, broader competencies and in the dynamics of the repeated associative experiment (Hu, 2002).

Thus, the associative experiment can be not only a means of building and evaluating foreign language competence, but also a tool for constructing concepts or individual associative-semantic field of the native or foreign language (Mubarakshina et al., 2016). Repeating such experiment can determine cognitive dynamics and dynamics of the sense of language during study of the language by students (Aghababyan, 2016). It is confirmed that the associative experiment can be used not only during evaluation, but also during development of foreign language competence. For this purpose, students learn obligatory paradigmatic relations, gain during training and communication the experience of establishing typical associations; developing new connections during professional activities (Aghababyan, 2016).

The opinion of scientists is confirmed, in which the associative experiment develops a possible flexible use of connections: "the first wordreaction, the second word-reaction, each subsequent one from the previous one; the whole chain of associations that coordinate themselves" (Mukhametzyanova \& Shayakhmetova, 2014).

Among negative aspects of the associative experiment as a method of linguodidactics should be distinguished contamination, blurring of nuclear values, so this method cannot be abused in teaching (Benjamin \& Rahman, 2016). It must be combined with classical methods of language learning and encourage bilinguals to build and use an individual thesaurus in changing contexts, living discourse.

\section{Conclusion}

Thus, analysis of modern neurocognitive approaches and their extrapolation into the field of building-evaluation of foreign language competencies with university students (with elements of implementation in the educational process) proved: for unprepared linguodidact in neuroscience the most valid is the associative experiment, a method that harmoniously combines and takes into account the actual linguistic and neurocognitive patterns of lexicon expansion. This method can be considered relatively universal and such that allows to "penetrate" into the individual conceptual "world" of the student, to determine his language profile and idiosyncrasy. 
Foreign Language Competence Development of University Students and its ... Ruslana DOVHANCHYNA, et al.

As a result of generalization of experimental data, it was proved: the connection between thematic relations and conceptual representations of concrete concepts does not always coincide, has individual differences.

It is also proved that syntagmatic and paradigmatic connections between words and their referents not only provide material for diagnosing the scope and flexibility of speech neural connections, but also develop the ability to spontaneously actualize usual and subjective meanings.

Accordingly, the neuro-approach at the level of linguodidactics in the evaluation and building of linguistic and communicative competencies of students is possible with appropriate and methodologically modeled actualization of logical-associative relations of free subjective meanings of words and obligatory (paradigmatic) meanings.

\section{References}

Abutalebi, J. (2008). Neural aspects of second language representation and language control. Acta psychologica 128(3), 466-478. https://doi.org/10.1016/j.actpsy.2008.03.014

Abutalebi, J., \& Green, D. (2007). Bilingual language production: The neurocognition of language representation and control. Journal of neurolinguistics, 20(3), 242-275. https://doi.org/10.1016/i.jneuroling.2006.10.003

Aghababyan, K. H. (2016). Investigation of dynamics of students' sense of language by word associative experiment method. Humanities in the 21st century: scientific problems and searching for effective bumanist technologies, 55-62. http://doi.org/10.15350/L 21/2/04

Benjamin, S., \& Rahman, R. R. A. (2016). Cumulative semantic interference for associative relations in language production. Cognition, 152, 20-31. https://www.psychologie.hu-berlin.de/de/prof/neuro/lit/rose

Björkman, A., \& Piekkari, R. (2009). Language and foreign subsidiary control: An empirical test. Journal of International Management, 15(1), 105-117. https://doi.org/10.1016/i.intman.2008.12.001

Creese, A., Blackledge, A., \& Takhi, J. (2014). The Ideal Native Speaker' Teacher: Negotiating Authenticity and Legitimacy in the Language Classroom. The Modern Language Journal, 98(4), 937-951. https://doi.org/10.1111/modl.12148

García, O. (2017). Reflections on Turnbull's Reframing of Foreign Language Education: Bilingual Epistemologies. International Journal of Bilingual Education and Bilingualism, 22(5), 628-638. https://doi.org/10.1080/13670050.2016.1277512 
Khirzoeva, Z. M. (2008). Assotsiativnyy eksperiment kak metod otsenki urovnya vladeniya inostrannym yazykom [An associative experiment as a assessing method of proficiency level in a foreign language]. Bulletin of the Dagestan State Pedagogical University, 3, 16-23. https://profspo.ru/magazines/7050/2008/3

Melnyk, N., Bidyuk, N., Kalenskyi, A., Maksymchuk. B., Bakhmat, N., Matviienko, O., Matviichuk, T., Solovyov, V., Golub, N., \&amp; Maksymchuk, I. (2019). Modely y orhanyzatsyone osobyne profesyonalne obuke vaspytacha u pojedynym zemsama Evropske Unyje y u Ukrajyny [Models and organizational characteristics of preschool teachers' professional training in some EU countries and Ukraine]. Zbornik Instituta za pedagoska istrazivanja, 51(1), 46-93. https://doi.org/10.2298/ZIPI1901046M

Melnyk, N., Maksymchuk, B., Gurevych, R., Kalenskyi, A., Dovbnya, S., Groshovenko, O., \& Filonenko, L. (2021). The Establishment and Development of Professional Training for Preschool Teachers in Western European Countries. Revista Romaneasca Pentru Educatie Multidimensionala, 13(1), 208-233. https://doi.org/10.18662/rrem/13.1/369

Mubarakshina, A., Fedorova, N., \& Fattahova, N. (2016). Associative-semantic field of 'nravstvennost' in modern Russian language. Journal of Language and Literature, 7(2), 280-284. https://core.ac.uk/download/pdf/197475322.pdf

Mukhametzyanova, L., \& Shayakhmetova, L. (2014). Application of Associative Experiment in Forming the Foreign Communicative Competence. English Language Teaching, 7(12), 60-64. https://core.ac.uk/download/pdf/197470323.pdf

Nerubasska, A., \& Maksymchuk, B. (2020). The Demarkation of Creativity, Talent and Genius in Humans: a Systemic Aspect. Postmodern Openings, 11(2), 240255. https://doi.org/10.18662/po/11.2/172

Nerubasska, A., Palshkov, K., \& Maksymchuk, B. (2020). A Systemic Philosophical Analysis of the Contemporary Society and the Human: New Potential. Postmodern Openings, 11(4), 275-292. https://doi.org/10.18662/po/11.4/235

Onishchuk, I., Ikonnikova, M., Antonenko, T., Kharchenko, I., Shestakova, S., Kuzmenko, N., \& Maksymchuk, B. (2020). Characteristics of Foreign Language Education in Foreign Countries and Ways of Applying Foreign Experience in Pedagogical Universities of Ukraine. Revista Romaneasca Pentru Educatie Multidimensionala, 12(3), 44-65. https://doi.org/10.18662/rrem/12.3/308

Purpura, J. E. (2016). Second and Foreign Language Assessment. The Modern Language Journal, 100 (1), 190-208. https://doi.org/10.1111/modl.12308 
Service, E., Simola, M., Metsänheimo, O., \& Maury, S. (2002). Bilingual working memory span is affected by language skill. European Journal of Cognitive Psychology, 14(3), 383-408. https://doi.org/10.1080/09541440143000140

Sternin, I. A. (2001). Metodika issledovaniya struktury kontsepta [The metodology of concept structure analysis].Metodologicheskie problemyi kognitivnoy lingvistiki [Methodological problems of cognitive linguistics]. Voronezh State University Press.

Takano, Y., \& Noda, A. (1993). A temporary decline of thinking ability during foreign language processing. Journal of Cross-Cultural Psychology, 24(4), 445462. https://doi.org/10.1177/0022022193244005

Thumb, A., \& Marbe, K. (1901). Experimentelle Untersuchungenüber die psychologishen Grundlagen der sprachlichen Analogiebildung. [Experimental studies on the psychological foundations of linguistic analogy formation]. W. Engelmann Publishing.

Turnbull, B. (2017). Towards new standards in foreign language assessment: learning from bilingual education. International Journal of Bilingual Education and Bilingualism, 23(2), 1-11. https://doi.org/10.1080/13670050.2017.1375891

Volk, S., Köhler, T., \& Pudelko, M. (2014). Brain drain: The cognitive neuroscience of foreign language processing in multinational corporations. Journal of International Business Studies, 45(7), 862-885.

https://doi.org/10.1057/jibs.2014.26 